\title{
Structural Features and Smoke Resistance of Water Mist Curtain of Upper Spray Nozzle
}

\author{
Xiaohua Jin, Lingbo Zhang*, Xiaoyan Li, Caixia Zhu
}

School of Energy and Environment, Zhongyuan University of Technology, Zhengzhou 450007, China

Corresponding Author Email: 2018108103@zut.edu.cn

https://doi.org/10.18280/ijht.380321

Received: 8 April 2020

Accepted: 29 June 2020

\section{Keywords:}

super-long tunnel, water mist system, upward sprinkler head, smoke exhaust system, smoke suppression performance, ceiling distance

\begin{abstract}
Due to its structural limitation, the super-long tunnel faces the difficulty in smoke suppression on the ceiling. For this, the authors aim to develop a water mist curtain with an upward sprinkler head and analyze its smoke suppression performance. FDS numerical simulation was conducted to analyze the changes over time of different parameters such as temperature, smoke spread, radiative heat flux density, $\mathrm{CO}$ volume fraction, and the distance between the sprinkler head and the ceiling, and explore the smoke-proof and fire extinguishing effect of the improved water mist curtain together with the tunnel's smoke exhaust system. The results show that with the spray flow rate of $12 \mathrm{~L} / \mathrm{min}$ and droplet size of $300 \mu \mathrm{m}$, the water mist system with upward sprinkler heads has a more efficient smoke suppression efficiency than the conventional one; the improved water mist system reduced the temperature at the tunnel ceiling by more than $40 \%$, and the $\mathrm{CO}$ volume fraction by about $33 \%$, thereby significantly decreasing the smoke density on the ceiling; it reduced the radiative heat flux density at a height of $2 \mathrm{~m}$ by about $47 \%$, and especially when coupled with the tunnel smoke exhaust system, the smoke suppression performance is better; the smoke volume fraction decreases with the distance between the sprinkler head and ceiling at the height of $5 \mathrm{~m}$ from the ground. The research findings provide a reference for the smoke suppression of the water mist system and smoke exhaust system in the future.
\end{abstract}

\section{INTRODUCTION}

Following the rapid development of tunnel construction in China, tunnel fire safety issue has gradually received extensive more attention from related researchers. In particular, the smoke exhaust system of super-long highway tunnels must meet the fire protection requirements to ensure the safe evacuation of people trapped in the fire. The tunnel ventilation in China has developed from transverse and semi-transverse ventilation to longitudinal ventilation. The common methods of smoke exhaust include natural smoke exhaust and mechanical smoke exhaust [1]. Fire resisting shutter and ceiling screen, as the common smoke-blocking facilities, cannot be used in the tunnels due to the particularity of the tunnel structure. But because of its flexibility, the water curtain system can be applied in the tunnel space to prevent smokes.

Some scholars conducted research on the water mist and proved its better effect of suppressing flame speed and pool fire [2-4]. Some others explored the fire extinguishing effect and influencing factors of water mist by establishing Froude's model, changing water mist parameters, adding chemical additives, or changing water mist characteristics etc. [5-8]. Yu et al. [9] studied the smoke control performance of the water curtain in the tunnel by changing the different parameters of the curtain, concluding that the different spray angles have a more significant impact on the sealing effect compared with its width, and the best spray angle is $30^{\circ}$ inclined to the fire source. Sun et al. [10] verified the effect of the water mist system in blocking the smoke and heat generated by the fire through the tunnel model experiment; in natural ventilation, the water mist system can effectively prevent the smoke from spreading, reduce the tunnel temperature, and ensure a great cooling effect of the system under a high water pressure, while it's not significant in longitudinal ventilation. Li and Ingason [11] analyzed the performance of the tunnel sprinkler system through a reduced size model and concluded that under the condition of longitudinal ventilation, high ventilation and low water flow are the main reasons that affect the performance of this system.

Zhang et al. [12] probed into the impact of water mist on fire extinguishing in urban tunnels and analyzed the spacings between different nozzle through experiments and simulations, to finally obtain the best nozzle spacing in different areas. Chen et al. [13] performed FDS simulation to explore the fire extinguishing effect of water mist in the utility tunnel from different angles of the nozzles, and found that the side spray has a better cooling effect and the water mist has a higher fire extinguishing effect at the nozzle's installation angle $\leq 50^{\circ}$. Zhong et al. [14] designed a transverse water mist system and studied its suppression effect on subway station fire and smoke through an experimental platform, to conclude that the transverse mist curtain reduces the ceiling flame length by about $40 \%$ with obvious smoke stratification, and increases heat insulation efficiency by about $10 \%$ compared with the longitudinal curtain. Cheng et al. [15] changed the parameters of the water mist system and investigated the smoke spread in tunnels through FDS numerical simulation to find that with the same particle size, the smoke suppression efficiency increases with the flow rate; with the flow rate unchanged, the cooling effect and visibility increase as the particle size decreases. Liu et al. [16] established a full-scale experiment to explore the fire extinguishing performance of water mist under different 
exhaust and ventilation conditions, and then conducted simulation to verify that water mist can extinguish the pool fire under the smoke exhaust conditions, but the fire extinguishing time is affected by the ventilation rate, and also to prove that the water mist can effectively reduce the flame temperature and save the trapped persons despite of the low visibility. Li et al. [17] carried out a multi-directional analysis of the smoke and heat generated by the fire in the fine water mist section of the medium-sized tunnel through model experiments, and verified that the fine water mist section with many rows of nozzles and high-water pressure produces a great smoke suppression efficiency. Ling et al. [18] combined the water mist curtain with the transverse ventilation system of the tunnel, and verified through simulation that this scheme can effectively suppress fire and smoke, and enable the trapped people to evacuate safely.

The water mist system enjoys a good smoke suppression effect. But due to its own structural limitation, it cannot prevent the smoke spreading around on the ceiling. To solve the problem, this paper aims to design a water mist system with upward sprinkler heads, forming a $360^{\circ}$ protective barrier. For this, the full-scale mathematical model of the tunnel based on FDS was constructed to explore the smoke suppression effect of the improved water mist system and the optimal installation distance from the ceiling. This study provides a reference for the design and application of the water mist system and smoke exhaust system etc. in the future.

\section{DESIGN OF UPWARD SPRINKLER HEADS FOR WATER MIST SYSTEM}

\subsection{Design ideas of sprinkler heads}

The sprinkler head of the existing automatic sprinkler system have good fire extinguishing effects. The sprinkler heads are mainly divided into three types: closed-type, opentype, and deluge-type. Most of them have only one nozzle, and the water droplet size is large, consuming more water. They are often used to extinguish fires, but the smoke-proof effect is not significant. Due to its structure particularity, the tunnel is difficult to install a fire wall, fire shutter or other smokeproof facilities. According to the Code for Fire Protection Design of Buildings [19], when it is difficult to set up a fire wall, the water curtain for fire separation can be used. The water mist system plays an important role in preventing smoke and can be used in the buildings that cannot be equipped with fire walls and fire shutters. Its sprinkler head is an improvement of the ordinary one, using multiple nozzles and spray water droplets to form a divergent water curtain with uniform thickness distribution.

Generally, the smoke rises from the fire source to the top of the tunnel and spreads around. The water mist system has a good smoke suppression and extinguishing effect, but not for the tunnel ceiling. The conventional sprinkler sprays water downwards, making the scattering angle of water spray difficult to exceed $180^{\circ}$, and limiting the coverage area. In this study, the water mist system with an upward sprinkler head was designed. The improved sprinkler head was designed mainly to cover the tunnel ceiling. Compared with the conventional one, it has a wider area of water droplets, and plays a role of more efficient smoke proof and fire control.

\subsection{Overview of sprinkler head structure}

The sprinkler head is designed by changing its type of connection with the water injection pipeline and the orientations of the nozzles inside the nozzle body, in order to improve the coverage range of the water mist and the smoke proof and fire extinguishing efficiency.

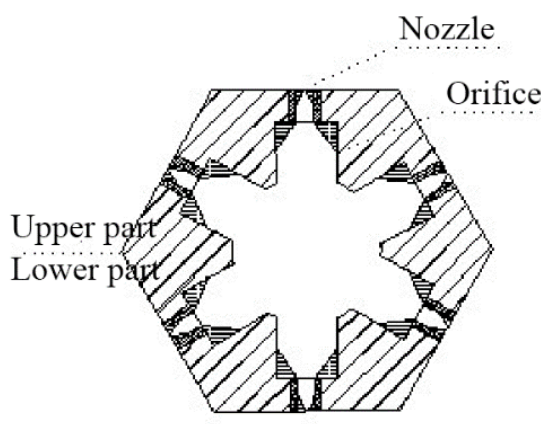

(a) Profile view

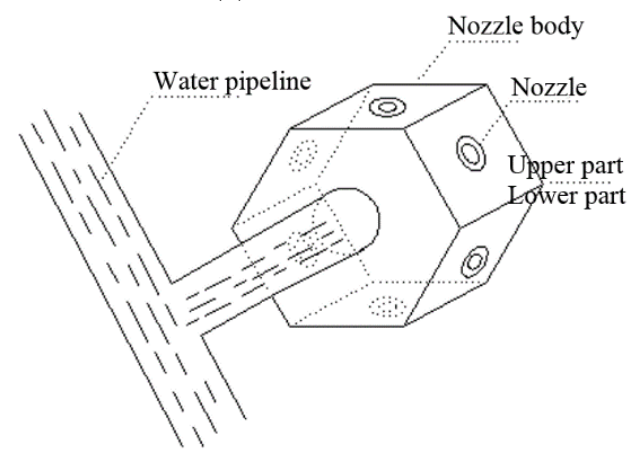

(b) Solid diagram

Figure 1. Structure diagram of upward sprinkler head

The upward sprinkler head is made of stainless steel. As shown in Figure 1(a), the profile of the nozzle body inside is a regular hexagon. There are six nozzles evenly distributed in a circular shape on six planes. The nozzle body is divided into the upper and lower parts: the upward nozzles of the upper part spray towards the ceiling, and the nozzles on both sides form a $45^{\circ}$ angle with the horizontal plane; the downward nozzles of the lower part spray towards the ground, and the nozzles on both sides form a $45^{\circ}$ angle with the horizontal plane. Figure 1 (b) shows a three-dimensional view of the sprinkler head. The water supply pipeline is parallel to the horizontal plane. The side end of the nozzle body is connected to the water supply pipeline through which the water flows into the internal orifice of the nozzle body. For the internal orifice, the diameter is reduced top down from the center to the nozzle outlet. Besides, it is a cone-shaped flow channel, showing an oblique cross-sectional view, so that the internal water flow generates turbulent flow, enters the nozzle through the internal orifice and then sprays from six nozzles. The orifice of nozzle body is connected through the thread and the misting nozzle. The nozzle hole is designed in a small size, to reduce the water droplet size and water consumption, and ensure a high-water pressure and spray speed, thereby producing a great misting effect. In this way, the sprayed water mist can form a $360^{\circ}$ coverage of water curtain plane, and plays the role of efficient smoke suppression and fire extinguishing. 
Conventional sprinkler heads are mostly used to extinguish fires in the lower part. Due to the space limitation, it cannot spray the ceiling space, which results in limited spray area and affects the smoke suppression effect. The new design in this paper fully considers the space between the sprinkler head and the ceiling, and solves this problem by changing the pressure and flow of the sprinkler head to set different heights from the ceiling etc. As a flexible and simple design, it can also be applied to other over-long or over-wide buildings where it is difficult to block smoke, and achieve the effective smoke proof and fire control.

\section{FDS-BASED TUNNEL SIMULATION}

\subsection{Model establishment}

Pyrosim was used to build the tunnel fire model and improve the sprinkler head of the water mist system, and FDS was adopted for calculating the simulation results. Finally, the built-in post-processing software Smokeview read and displayed the results and animation. FDS software is the most widely used software in the field of fire. Among the engineering applications and scientific literatures, $90 \%$ or more of fire simulations are completed by FDS [20].

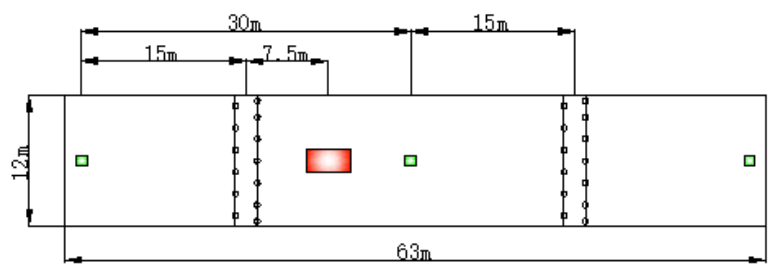

Figure 2. Layout of tunnel fire-fighting equipment

The built full-scale model was a one-way two-lane superlong tunnel, as shown in Figure 2. The tunnel section is $12 \mathrm{~m}$ wide and $6 \mathrm{~m}$ high. The $63 \mathrm{~m}$ section in the middle of the superlong tunnel was selected for simulation. A fire source with a length of $2 \mathrm{~m}$, a width of $2 \mathrm{~m}$, and a height of $1 \mathrm{~m}$ was simulated to be a passenger car with a fire source area of 12 square meters. According to the Code for Fire Protection Design of Buildings, the fire source power of cars is $5 \mathrm{MW}$, and that of buses is $20 \mathrm{MW}$, so the fire source power was set to $18 \mathrm{MW}$. The empirical value of the grid size was set to $1 / 4-1 / 16$ of the characteristic fire diameter. The fire source diameter $\mathrm{D}^{*}$ is calculated as:

$$
D^{*}=\left(\frac{\dot{Q}}{\rho_{\infty} c_{p} T_{\infty} \sqrt{g}}\right)^{\frac{2}{5}}
$$

where:

$\dot{Q}$-the heat release rate of the fire source, $\mathrm{KW}$;

$\rho_{\infty}$-air density, $1.2 \mathrm{~kg} / \mathrm{m}^{3}$;

$\mathrm{c}_{\mathrm{p}}$-specific heat of air, $1 \mathrm{~kJ} /(\mathrm{kg} * \mathrm{~K})$;

$T_{\infty}$-ambient air temperature, $293 \mathrm{~K}$;

g-acceleration of gravity, taken as $9.81 \mathrm{~m} / \mathrm{s}^{2}$

Taking $1 / 10$ of the characteristic fire diameter, the grid size was calculated to be $\mathrm{d}=0.31 \mathrm{~m}$. To save calculation time, the grid size was set to $0.3 \mathrm{~m} * 0.3 \mathrm{~m} * 0.3 \mathrm{~m}$, and the number of grids was 168,000 .

The Code for Design of Sprinkler System [21] specifies that the fire compartment drencher system should ensure the width of the water curtain $\geq 6 \mathrm{~m}$. In this study, the sprinkler heads were set in 2 rows with the spacings between rows and between nozzles for $2 \mathrm{~m}$, and spacing between the wall nozzles and the wall for $1 \mathrm{~m}$. The nozzle flow rate was $12 \mathrm{~L} / \mathrm{min}$, and the droplet size was $300 \mu \mathrm{m}$. The sprinkler head was improved by changing the number and orientation of the nozzles in the water spray model. According to the Technical codes for Water Mist Fire Extinguishing System [22], the time from the start of the fire extinguishing system to the water outlet of the most unfavorable nozzle in the pipe network should not exceed $30 \mathrm{~s}$, so the start time of the simulated nozzles was set to $30 \mathrm{~s}$.

In the Code for Fire Protection Design of Buildings, it's specified that for tunnels with a length of more than $3000 \mathrm{~m}$, two smoke exhaust methods should be adopted: longitudinal segmented smoke exhaust and key smoke exhaust. The distance between the smoke vents of the tunnel is mostly $30 \mathrm{~m}$ $60 \mathrm{~m}$ [23], so the distance $30 \mathrm{~m}$ was used in this design. Considering that adjacent smoke vents need to be opened in case of a fire, a total of three smoke vents were set, and the water mist curtain was set between the two; the fire source was between the water mist system and the smoke vent, i.e., the most unfavorable position of the smoke vent and the water mist system. Detection equipment was set at $2 \mathrm{~m}$ on the left and right sides of the water mist system.

Thermocouples, weather detection equipment, slices of temperature, smoke and water spray particles were set at $2 \mathrm{~m}$ from the left and right of the water mist system (the left side is away from the fire source) to detect temperature, radiative heat flux density, $\mathrm{CO}$ volume fraction, and smoke volume fraction etc. The ambient temperature was $20^{\circ} \mathrm{C}$ by default, and the inner wall of the tunnel was made of concrete.

\subsection{Simulated working conditions}

The simulation was conducted mainly to study the effect of the upward sprinkler head-type water mist system on the smoke suppression and fire extinguishment in the super-long tunnel. The internal smoke exhaust system was also used to monitor the flow of smoke, while different parameters such as the spread of smoke, smoke volume fraction, $\mathrm{CO}$ volume fraction, and temperature were observed to analyze the efficiency of smoke suppression and exhaust. Therefore, the working conditions were set from three aspects: (1) different forms of sprinkler heads; (2) smoke exhaust system; (3) the distance between the sprinkler head and the ceiling, as shown in Table 1 for details.

Table 1. Setting of working conditions

\begin{tabular}{|c|c|c|c|}
\hline $\begin{array}{l}\text { Working } \\
\text { condition }\end{array}$ & $\begin{array}{c}\begin{array}{c}\text { Forms of } \\
\text { sprinkler } \\
\text { heads }\end{array} \\
\end{array}$ & $\begin{array}{c}\text { Smoke } \\
\text { exhaust } \\
\text { system } \\
\end{array}$ & $\begin{array}{c}\text { Distance between } \\
\text { the sprinkler head } \\
\text { and ceiling/m }\end{array}$ \\
\hline 1 & No & No & No \\
\hline 2 & $\begin{array}{c}\text { Conventional } \\
\text { type }\end{array}$ & No & 0.2 \\
\hline 3 & $\begin{array}{c}\text { Conventional } \\
\text { type }\end{array}$ & Yes & 0.2 \\
\hline 4 & $\begin{array}{l}\text { Upward } \\
\text { spray type }\end{array}$ & No & 0.5 \\
\hline 5 & $\begin{array}{l}\text { Upward } \\
\text { spray type }\end{array}$ & Yes & 0.5 \\
\hline 6 & $\begin{array}{l}\text { Upward } \\
\text { spray type }\end{array}$ & Yes & 0.8 \\
\hline 7 & $\begin{array}{l}\text { Upward } \\
\text { spray type }\end{array}$ & Yes & 1.2 \\
\hline
\end{tabular}




\section{ANALYSIS OF SIMULATION RESULTS}

\subsection{Temperature}

The temperature of the fire site is an important criterion for the safe evacuation of personnel. Generally, the personnel can safely evacuate with the temperature less than $60^{\circ} \mathrm{C}$ at a height of $2 \mathrm{~m}$ in the tunnel. Figure 3 shows the temperature distribution at the height of $2 \mathrm{~m}$ for the working conditions 1 to 5. The ambient temperature was $20^{\circ} \mathrm{C}$. In the initial stage of the fire, the temperature of each working condition rose rapidly, with an increase of about $10^{\circ} \mathrm{C}$. On the whole, compared with other working conditions, the overall temperature of working condition 1 was at the highest point, showing no downward trend, and the maximum temperature exceeded $34^{\circ} \mathrm{C}$; With no use of any fire extinguishing equipment, the temperature of the fire site slowly rose over time, and finally stabilized at $33^{\circ} \mathrm{C}$. After 30 s, the water curtain system and the smoke exhaust system were turned on. At this time, the temperature of the remaining 4 working conditions has significantly decreased by about $5^{\circ} \mathrm{C}$, indicating that the water curtain system and the smoke exhaust system can help reduce the temperature of the fire site. Also, the overall temperature of working condition 2 was lower than that of condition 1, indicating that the water curtain system can reduce smoke temperature in some degree, while the temperature curve of working condition 5 was at the lowest position. Therefore, the simultaneous operation of both water curtain and smoke exhaust system can effectively reduce the temperature of fire site.

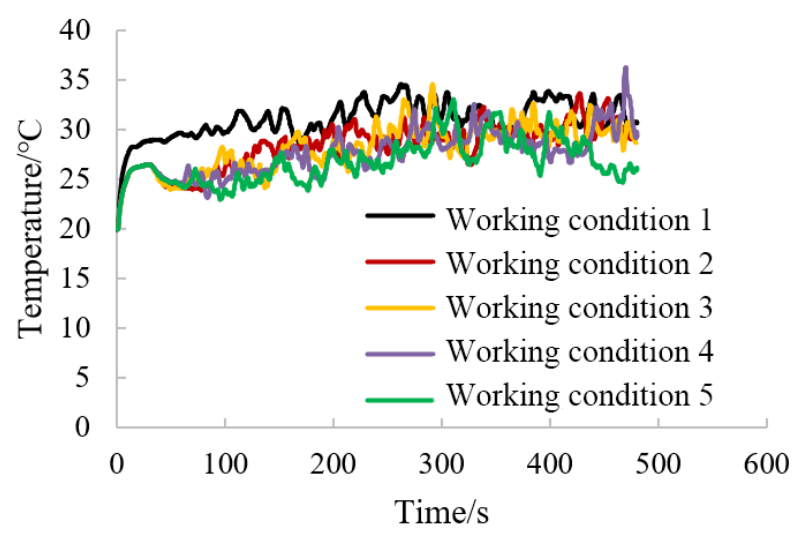

Figure 3. Temperature change at $2 \mathrm{~m}$ height of tunnel

Figure 4 shows the temperature of each measuring point at a height of $2 \mathrm{~m}-6 \mathrm{~m}$ from the ground in the working condition 1,2 , and 4 . Comparing these three working conditions, it can be seen that when the tunnel was on fire, the fire site temperature sharply increased and the temperature at the ceiling can exceed $250^{\circ} \mathrm{C}$. In working condition 1 without any fire extinguishing system, the overall temperature at each height rose steadily. After using the water mist system, the water mist vaporized and took away most of the heat, causing the temperature of the fire site to drop sharply, especially at the ceiling. In working condition 4 , the temperature at the ceiling dropped from about $250^{\circ} \mathrm{C}$ to $150^{\circ} \mathrm{C}$, and with the passage of time, the temperature of the fire site fluctuated around $150^{\circ} \mathrm{C}$, so its temperature drop is the most significant, followed by working condition 2 , with a drop of about $60^{\circ} \mathrm{C}$. In addition, the temperatures on each measuring point at different heights varied significantly. The temperature at $5 \mathrm{~m}$ height in working condition 4 was about $80^{\circ} \mathrm{C}$ lower than that at $6 \mathrm{~m}$; in this working condition, the temperature at $5 \mathrm{~m}$ height could exceed $130^{\circ} \mathrm{C}$ in case of a fire, but it dropped significantly after staring the water mist system, and then stabilized at around $75^{\circ} \mathrm{C}$. The temperature at a height below $3 \mathrm{~m}$ in the three working conditions was below $60^{\circ} \mathrm{C}$, meeting the fire protection requirements, and the trapped persons can be safely evacuated. The temperature drop in each measuring point at different heights in working condition 4 was the largest, followed by working condition 2 , and there was no temperature drop in working condition 1 . Thus, the water curtain system can effectively reduce the temperature of the fire field, and the upward sprinkler head-type water mist system is more efficient than the conventional one in reducing the fire field temperature.

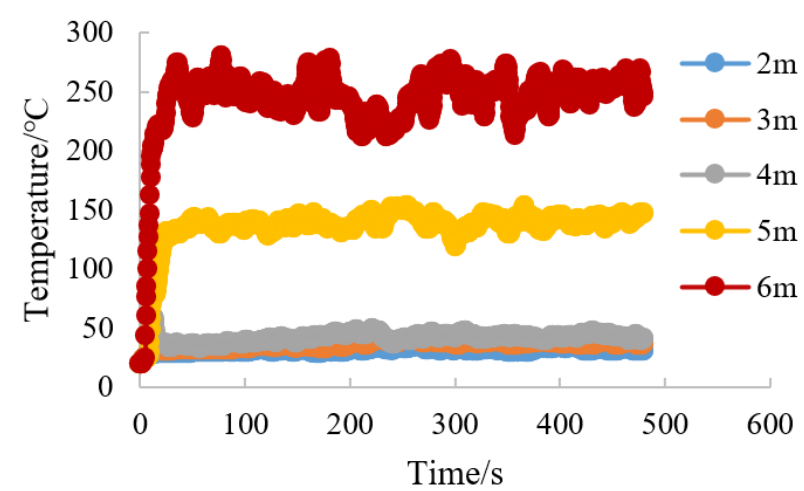

(a) Working condition 1

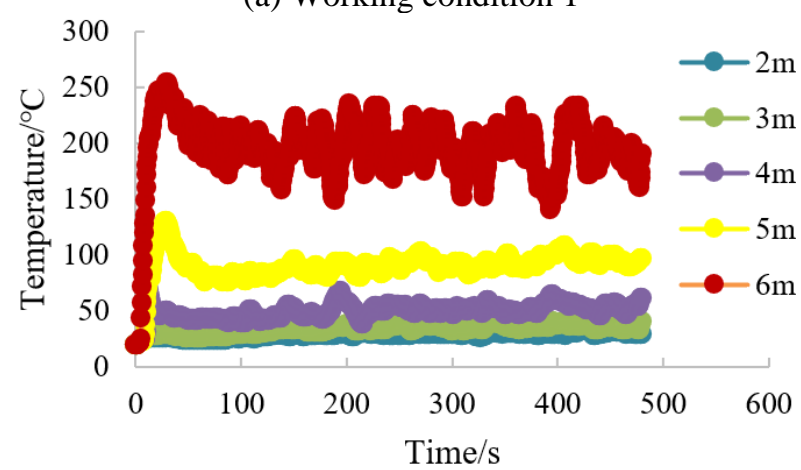

(b) Working condition 2

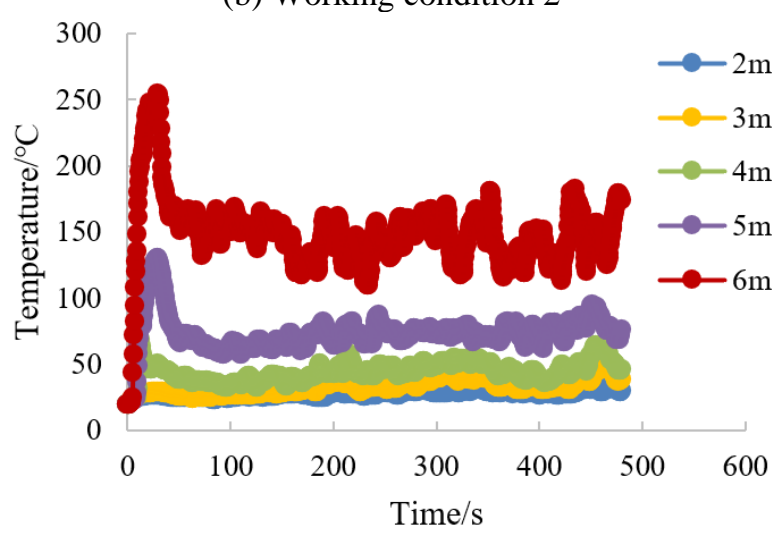

(c) Working condition 4

Figure 4. Temperature changes at different heights of the tunnel 


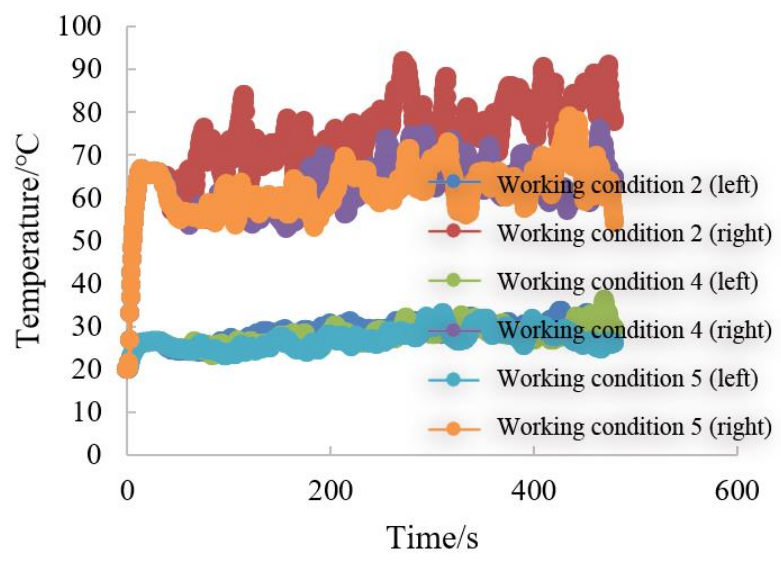

Figure 5. Temperature changes on both sides of the water mist system

Figure 5 shows the temperature changes at a height of $2 \mathrm{~m}$ on the left and right sides of the water mist system in the working condition 2, 3, and 5. The left side is away from the fire source. It can be seen from the figure that after the fire broke out, the water curtain system and the smoke exhaust system were not turned on, and the temperature of each working condition rose sharply, reaching up to about $70^{\circ} \mathrm{C}$, which was not conducive to the safe evacuation of personnel; after 30s, the temperature dropped significantly, and there were huge differences of temperature on the left and right sides of the water mist curtain. That is, the temperature on the left side fluctuated little and showed a stable trend, while the temperature on the right side in the three working conditions was much higher than on the left side, indicating that the water mist system can effectively reduce the temperature of the fire site and smoke, and the trapped personnel can evacuate safety on the left side of the water mist curtain because of its temperature lower than $40^{\circ} \mathrm{C}$. On both sides of water mist curtain, the working condition 2 had the highest temperature, followed by working condition 4 , and the working condition 5 had the lowest temperature. Thus, the cooling effect of the improved water mist system is slightly higher than that the conventional one; from the lowest temperature in working condition 5, its fire extinguishing efficiency is the highest under the combined action of the water curtain system and the smoke system.

\subsection{Smoke spreading}

The smoke spreading in different working conditions was observed, to analyze the smoke suppressing effect of the water curtain system and the smoke exhaust system. Figure 6 shows the smoke spreading in working conditions 1-5 when on fire for $90 \mathrm{~s}$. Without the water curtain system and the smoke exhaust system, the smoke spread across the top of the tunnel, and the smoke diffused rapidly from the top of the fire source to the surroundings, with a downward trend, because it is difficult to set up the ceiling screen in the tunnel. It can be clearly seen that the smoke layer of working condition 1 was denser than other working conditions. Whereas, in the working conditions 2-5, after turning on the water curtain system, it can block part of the upstream smoke on the right side, and dilute the ceiling smoke on the left side. The smoke below the water mist curtain has a downward trend, because the curtain has a downward impulse to produce entrainment, causing the smoke to generate turbulence, and the smoke is flushed downward.
When turning on the water curtain system and the smoke exhaust system simultaneously, the thickness of the smoke layer is significantly reduced, more smoke can be taken away, and the smoke layer is thinner, but the smoke is not completely blocked. Therefore, it can be improved by increasing the pressure and flow rate of the water mist system.

The slices of temperature in Figure 6 reflects the temperature on the left side of the water mist curtain. It can be seen that the smoke temperature of working condition 1 was the highest, up to $270^{\circ} \mathrm{C}$, followed by conditions 2 and 3, and working conditions 4 and 5 had the lowest temperature, only $170^{\circ} \mathrm{C}$. This further indicates that the upward sprinkler head has a greater cooling range and smoke proof effect than the conventional one.
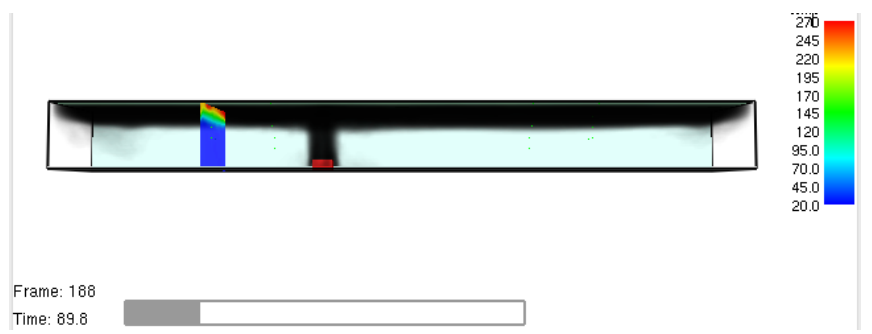

(a) Working condition 1
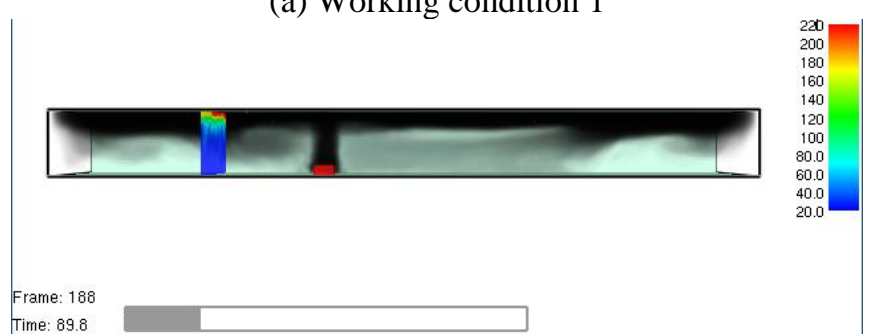

(b) Working condition 2
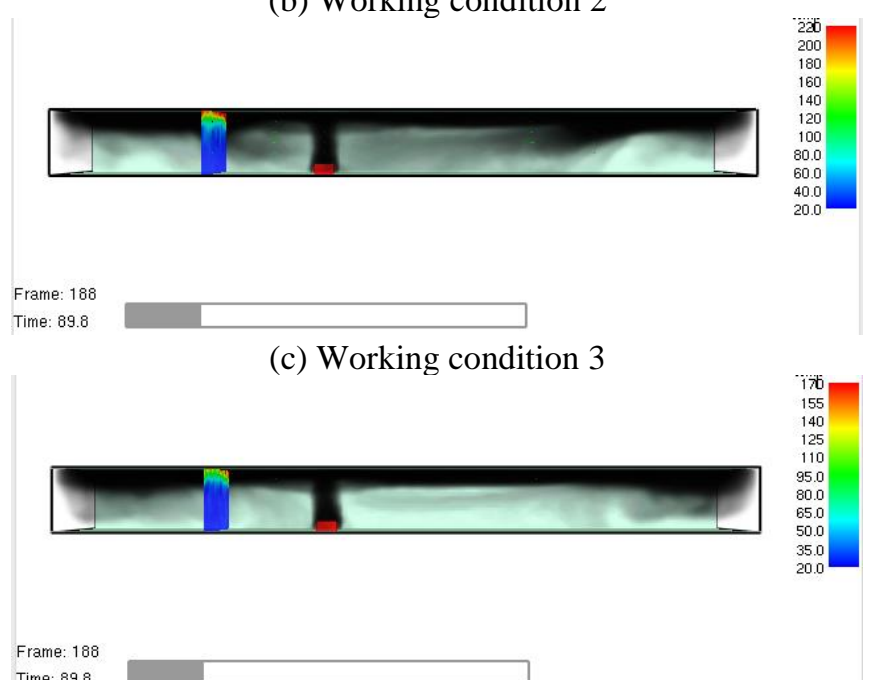

(d) Working condition 4
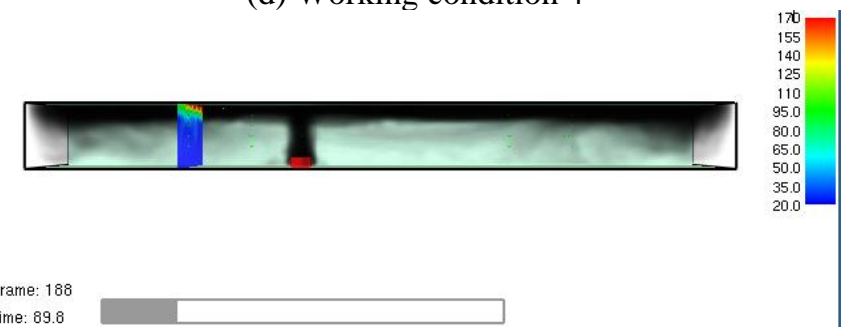

(e) Working condition 5

Figure 6. Schematic diagram of tunnel smoke spreading 


\subsection{Radiative heat flux density}

Figure 7 compares the radiative heat flux density values in working conditions 1,4 , and 5, and shows the values at the height of $2 \mathrm{~m}$ and $5 \mathrm{~m}$ on both sides of the water mist curtain, respectively.

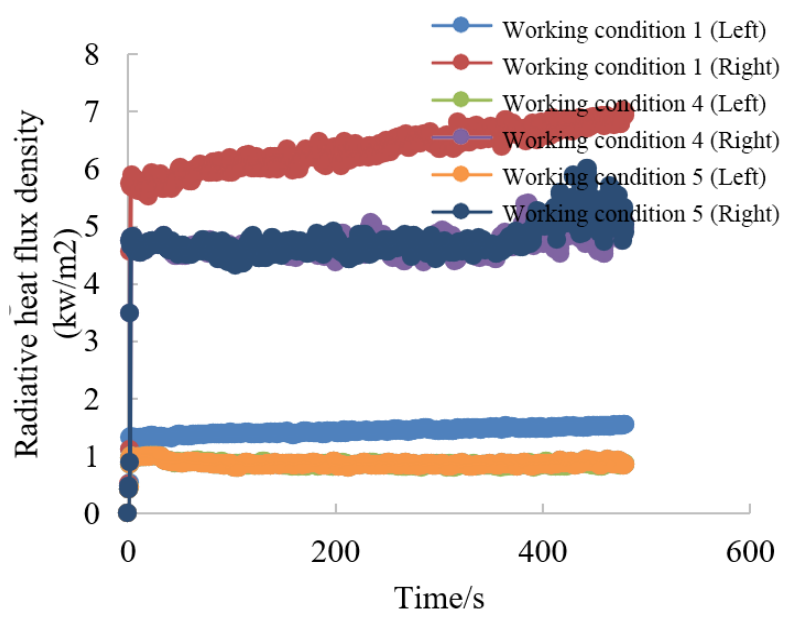

(a) At the $2 \mathrm{~m}$ height of tunnel

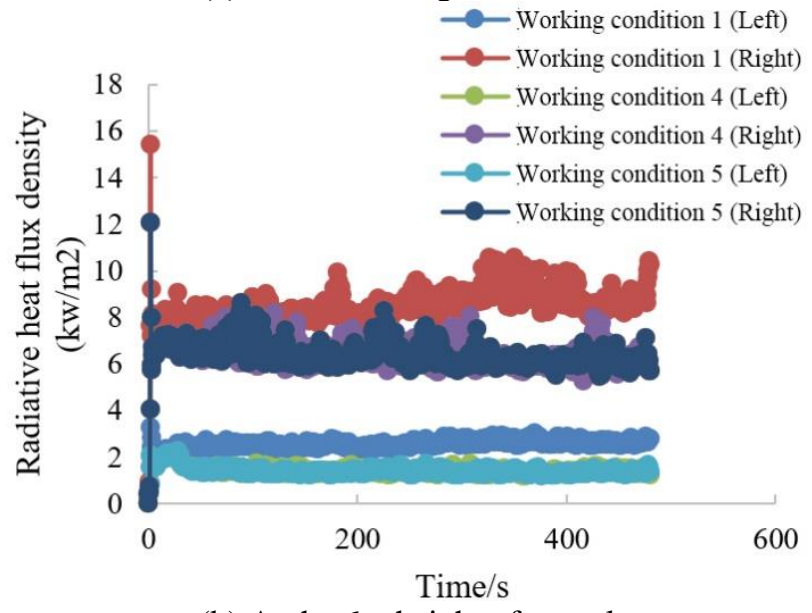

(b) At the $6 \mathrm{~m}$ height of tunnel

Figure 7. Variation curve of radiative heat flux density at different heights in the tunnel

Figure 7(a) shows the radiative heat flux density on the left and right sides of the water mist curtain at a height of $2 \mathrm{~m}$ in the tunnel. It can be seen from the figure that in case of a fire, the thermal fluid in each working condition generates radiation instantaneously. In the working condition 1, the radiative heat flux density on the right side of water curtain rapidly rose to $6 \mathrm{kw} / \mathrm{m}^{2}$, exceeded $7 \mathrm{kw} / \mathrm{m}^{2}$ after 8 minutes, and then slowed down with time; the value on the left side was about $1.5 \mathrm{kw} / \mathrm{m}^{2}$, with an upward trend. The radiative heat flux density on the right side in working condition 4 and 5 was similar. With time, there was no obvious increase or decrease in the data of the two, and the value on the right side in the two working conditions stabilized at about $4.8 \mathrm{kw} / \mathrm{m}^{2}$. Whereas, on the left side, the density between the two had no much difference, and the overall value was stable at $0.8 \mathrm{kw} / \mathrm{m}^{2}$. The comparison found that in the two working conditions, the radiative heat flux density on the left or right side is far lower than that of working condition 1 . This indicates that the water mist with the upward sprinkler head can block and reduces part of the heat flow radiation in the fire field, and decrease the radiation damage of the harmful gas.
Figure 7(b) shows the radiative heat flux density on the left and right sides of the water mist curtain at a height of $6 \mathrm{~m}$ in the tunnel. It can be clearly seen that it's generally higher than that at a height of $2 \mathrm{~m}$, on both the left side and right side of the water curtain. This is due to the denser smoke near the ceiling, producing more radiation than areas at lower heights. In Figure 7(b), the highest radiative heat flux density was still on the right side in Working Condition 1, exceeding $15.5 \mathrm{kw} / \mathrm{m}^{2}$, and then decreased and stabilized as a whole, with a steady increase over time. The overall radiative heat flux density of the working conditions 4 and 5 was lower than condition 1 , and showed a downward trend with time, indicating that the water mist system can block the heat flow radiation. The gas density on both sides of the water mist curtain in working condition 5 was slightly lower than that in working condition 4 , indicating that the smoke exhaust system can discharge part of the smoke and reduce the smoke heat flow radiation. From this, the combination of water curtain system and the smoke exhaust system can effectively block the smoke and extinguish the fire, reduce the gas heat flow radiation in the fire site, and help people to evacuate safely.

\subsection{CO volume fraction}

The $\mathrm{CO}$ volume fraction is usually used as an important indicator to determine the safe evacuation of people in case of a fire.

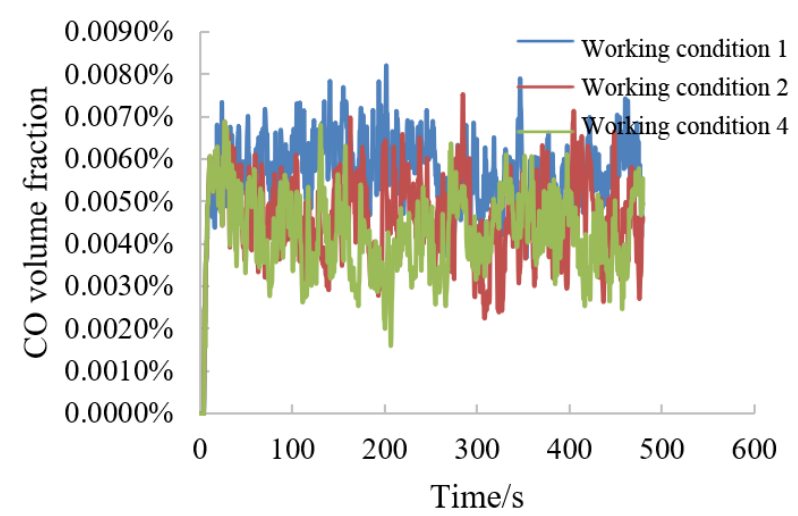

(a) Working conditions 1, 2, and 4

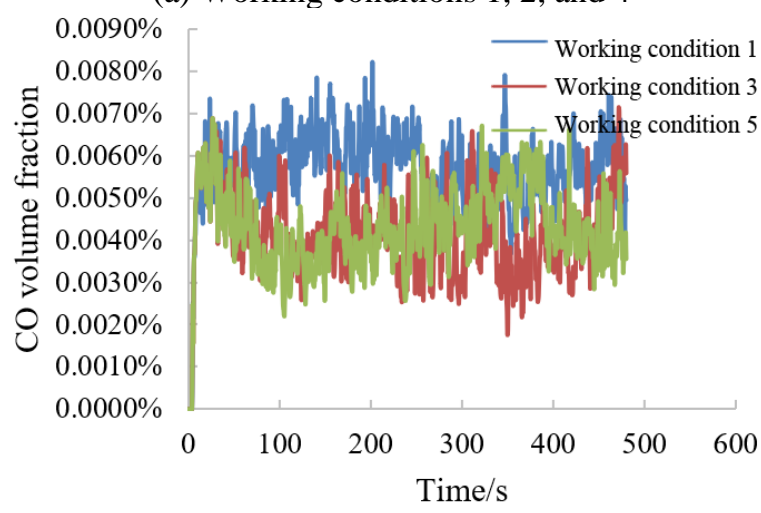

(b) Working conditions 1, 3, and 5

Figure 8. CO volume fraction at the tunnel ceiling

Figure 8 (a) shows the volume fraction of $\mathrm{CO}$ at the ceiling in the working conditions 1,2 , and 4 . It can be seen from the figure that after the fire broke out, the $\mathrm{CO}$ volume fraction rose sharply in a short period of time, and stabilized with time, and the values fluctuated greatly; the overall $\mathrm{CO}$ volume fraction of working condition 1 was the highest, fluctuating around, 
that of working condition 2 was about 10ppm lower than working condition 1 , and that of working condition 4 was about 20ppm lower than working condition 1. The data shows that without the water curtain system and the smoke exhaust system, the ceiling has a higher smoke density and $\mathrm{CO}$ volume fraction; after using the water curtain system, the water mist forms downward impulse to produce entrainment, and flushes the smoke downwards, so that the ceiling air flow is turbulent, the $\mathrm{CO}$ volume fraction is reduced overall, and the upward sprinkler head-type water mist system is more efficient in reducing the $\mathrm{CO}$ volume fraction.

Figure 8(b) shows the $\mathrm{CO}$ volume fraction at the ceiling of the working conditions 1,3 , and 5. As a whole, the $\mathrm{CO}$ volume fraction of working condition 1 was higher than conditions 3 and 5. By comparing Figure 8(a) and 8(b), the $\mathrm{CO}$ volume fraction of the working conditions 2 and 4 was higher than 3 and 5. The data indicates that the smoke exhaust system can discharge the smoke from the smoke vent, and reduce the $\mathrm{CO}$ volume fraction in the fire site. Under the dual action of the water curtain system and the smoke exhaust system, the smoke proof and fire extinguishing efficiency is higher.

\subsection{The distance between the sprinkler head and the ceiling}

\subsubsection{Particle distribution of smoke and water spray}

Figure 9 shows the distribution of smoke particles and water spray particles in the $5 \mathrm{~min}$ after the fire, with the distance between the sprinkler head and ceiling of $0.5 \mathrm{~m}, 0.8 \mathrm{~m}$, and $1.2 \mathrm{~m}$ respectively.

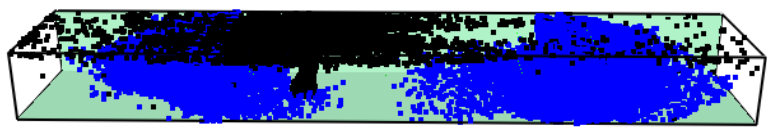

(a) Working condition 5

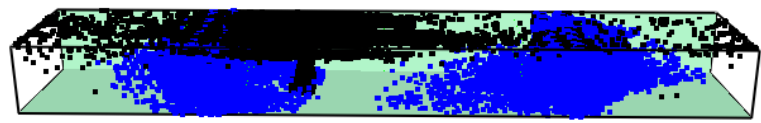

(b) Working condition 6

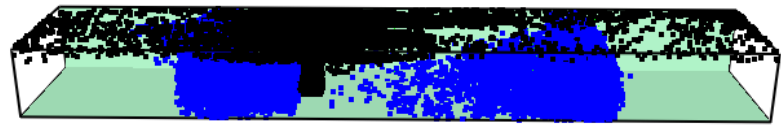

(c) Working condition 7

Figure 9. Cloud diagram of the distribution of tunnel smoke and water spray particles

It can be seen from the figure that after the fire broke out, the smoke rose from the fire source to the top of the tunnel and gathered in a large amount on the top of the tunnel, spreading around over time. The water mist system produced a large amount of water spray to form a water curtain barrier, and two water mist curtains at a distance of $30 \mathrm{~m}$ blocked most of the smoke on the side of the fire source and prevented the smoke from spreading farther. In the figure, the three smoke vents of the smoke exhaust system separated by $30 \mathrm{~m}$ were evenly distributed on both sides and the middle of the tunnel. They discharge a large amount of smoke, lowering the smoke density near the smoke vent and reducing the smoke particles. The comparison found that working condition 5 had fewer smoke particles on the outside of the water mist curtain (far from the fire source side), indicating a better smoke blocking effect; the working condition 6 was not much different from working condition 5, and working condition 7 was slightly worse. Thus, for the water mist systems under the same nozzle flow and pressure, the farther away from the ceiling, the worse the smoke blocking effect. It's finally concluded that when the water mist system and the smoke exhaust system are turned on simultaneously, the upward sprinkler head-type water mist system with the nozzle flow rate of $12 \mathrm{~L} / \mathrm{min}$ and the droplet size of $300 \mu \mathrm{m}$ can effectively prevent the smoke spread at the distance of $0.5 \mathrm{~m}$ or $0.8 \mathrm{~m}$ from the ceiling.

\subsubsection{Smoke volume fraction}

Figure 10 shows and compares the smoke volume fraction at the heights of $5 \mathrm{~m}$ and $6 \mathrm{~m}$ on the left side of water mist curtain under working conditions 5-7. In Figure 10(a), the smoke volume fraction in all working conditions increased sharply after the fire broke out, and then stabilized between 200ppm-400ppm using the water mist curtain, showing no significant difference between them. This indicates that the water mist curtain has a good smoke blocking effect on the ceiling.

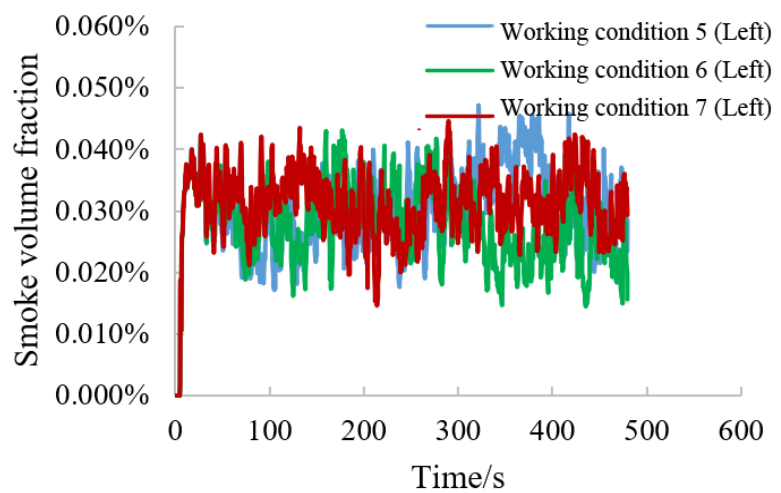

(a) At $6 \mathrm{~m}$ height in the tunnel

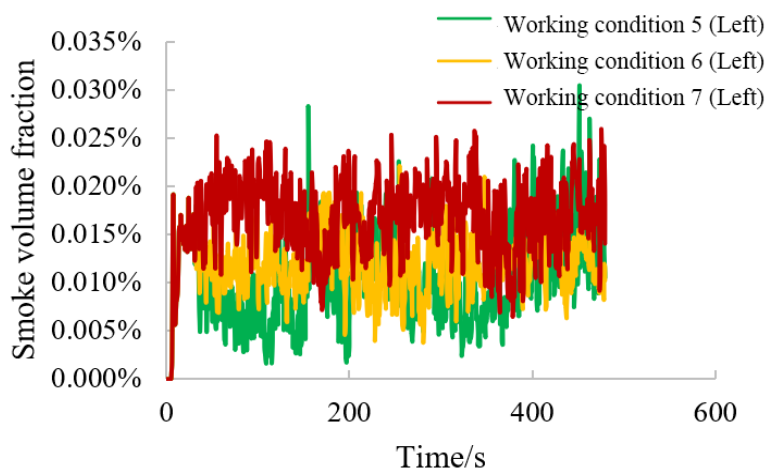

(b) At $5 \mathrm{~m}$ height in the tunnel

Figure 10. Variation curve of smoke volume fraction at different heights in the tunnel

Figure 10(b) shows that the smoke volume fraction in each working condition is lower than that in Figure 10(a). It can be seen from Figure 10(b) that the smoke fraction volume at a height of $5 \mathrm{~m}$ rose rapidly after the fire, and then stabilized over time with the use of the water mist curtain. The comparison found that the smoke volume fraction in working condition 7 was higher than condition 6 , and that of condition 5 was the smallest. This shows that when the upward sprinkler head-type water mist system with the nozzle flow rate of $12 \mathrm{~L} / \mathrm{min}$ and the droplet size of $300 \mu \mathrm{m}$ is turned on together with the smoke exhaust system, the smaller the distance from the ceiling, the lower the smoke volume fraction at a height of $5 \mathrm{~m}$. 


\section{CONCLUSIONS}

(1) The water mist system can significantly reduce the temperature of the fire site, especially on the upper part of the tunnel. The conventional water mist system can reduce the temperature at the ceiling by $24 \%$, while the improved water mist curtain with upward sprinkler heads can reduce the ceiling temperature by $40 \%$, and the temperature at a height of $5 \mathrm{~m}$ by about $42 \%$. Under the coupling effect of the improved water curtain system and the smoke exhaust system, the cooling efficiency reaches the highest.

(2) At the height of $2 \mathrm{~m}$ and $5 \mathrm{~m}$ in the tunnel, the radiative heat flux density on the left and right sides of the improved water mist curtain was significantly reduced; at the height of $2 \mathrm{~m}$, it's reduced by about $31 \%$ on the right side of the water curtain and by about $47 \%$ on the left side. Moreover, under the dual action of the water curtain system and the smoke exhaust system, the efficiency of reducing the radiative heat flux density in the fire field becomes higher.

(3) The $\mathrm{CO}$ volume fraction at the ceiling of the tunnel is significantly reduced by about $17 \%$ using a conventional water mist curtain. With the upward sprinkler head in the water mist system, the CO volume fraction is reduced by about $33 \%$. The comparison shows that the simultaneous operation of the water curtain system and the smoke exhaust system can effectively reduce the $\mathrm{CO}$ volume fraction in the fire field.

(4) The water mist system with the upward sprinkler head can effectively block the spread of smoke, reduce the smoke volume fraction at the ceiling, and dilute the smoke at the ceiling. Combined with the smoke exhaust system, the water mist system with the nozzle flow rate of $12 \mathrm{~L} / \mathrm{min}$ and the droplet size of $300 \mu \mathrm{m}$ can well block the ceiling smoke as the distance between the water mist curtain and ceiling is 0.5 or 0.8 . At a height of $5 \mathrm{~m}$ from the ground, the smoke volume fraction decreases as the distance between the sprinkler head and the ceiling decreases.

\section{REFERENCES}

[1] Yang, L., Yang, Y.Y., Wei, L.W., Liu, J.L., Li, L.J. (2019). Review on influencing factors of mechanical smoke exhaust effect of highway tunnel. Journal of Wuhan University of Technology (Information \& Management Engineering), 41(5): 479-484. https://doi.org/10.3963/j.issn.2095-3852.2019.05.004

[2] Yoshida, A., Okawa, T., Ebina, W., Naito, H. (2015). Experimental and numerical investigation of flame speed retardation by water mist. Combustion and Flame, 162(5): 1772-1777.

https://doi.org/10.1016/j.combustflame.2014.11.038

[3] Jenft, A., Collin, A., Boulet, P., Pianet, G., Breton, A., Muller, A. (2014). Experimental and numerical study of pool fire suppression using water mist. Fire Safety Journal, 67:

$1-12$. https://doi.org/10.1016/j.firesaf.2014.05.003

[4] Gupta, M., Pasi, A., Ray, A., Kale, S.R. (2013). An experimental study of the effects of water mist characteristics on pool fire suppression. Experimental Thermal and Fluid Science, 44: 768-778. https://doi.org/10.1016/j.expthermflusci.2012.09.020

[5] Yu, H.Z. (2012). Froude-modeling-based general scaling relationships for fire suppression by water sprays. Fire
Safety Journal, 47

$1-7$.

https://doi.org/10.1016/j.firesaf.2011.09.006

[6] Yoshida, A., Kashiwa, K., Hashizume, S., Naito, H. (2015). Inhibition of counterflow methane/air diffusion flame by water mist with varying mist diameter. Fire Safety Journal, 71: 217-225. https://doi.org/10.1016/j.firesaf.2014.11.030

[7] Joseph, P., Nichols, E., Novozhilov, V. (2013). A comparative study of the effects of chemical additives on the suppression efficiency of water mist. Fire Safety Journal, 58: 221-225. https://doi.org/10.1016/j.firesaf.2013.03.003

[8] Gupta, M., Rajora, R., Sahai, S., Shankar, R., Ray, A., Kale, S.R. (2012). Experimental evaluation of fire suppression characteristics of twin fluid water mist system. Fire Safety Journal, 54: 130-142. https://doi.org/10.1016/j.firesaf.2012.08.007

[9] Yu, L.X., Liu, F., Beji, T., Weng, M. C., Merci, B. (2018). Experimental study of the effectiveness of air curtains of variable width and injection angle to block fire-induced smoke in a tunnel configuration. International Journal of Thermal Sciences, 134: 13-26. https://doi.org/10.1016/j.ijthermalsci.2018.07.044

[10] Sun, J., Fang, Z., Tang, Z., Beji, T., Merci, B. (2016). Experimental study of the effectiveness of a water system in blocking fire-induced smoke and heat in reduced-scale tunnel tests. Tunnelling and Underground Space Technology, 56: 34-44. https://doi.org/10.1016/j.tust.2016.02.005

[11] Li, Y.Z., Ingason, H. (2013). Model scale tunnel fire tests with automatic sprinkler. Fire Safety Journal, 61: 298313. https://doi.org/10.1016/j.firesaf.2013.09.024

[12] Zhang, J., Wu, S.H., Yang, M., Xiong, Z. (2018). Research on influence of sprinkler spacing on water mist fire extinguishing in urban tunnel. Journal of Safety Science and Technology, 14(12): 119-123. https://doi.org/10.11731/j.issn.1673-193x.2018.12.019

[13] Chen, Y.H., Li, T.F., Yang, M., Zhu, W.J. (2020). Influence of sprinkler installation angle on water mist extinguishing fire in utility tunnel. Fire Science and Technology, $39(1)$ : $70-73$. https://doi.org/10.3969/j.issn.1009-0029.2020.01.020

[14] Zhong, W., Ma, Z.X., Xu, S.G., Lian,g, T.S., Zhao, J. (2020). Effectiveness of applying horizontal fine water mist curtain to suppress jet flame on ceiling in case of fire in metro station. China Railway Science, 41(1): 126-133. https://doi.org/10.3969/j.issn.1001-4632.2020.01.17

[15] Chen, M., Li, Y., Ren, Y.X. (2019). Analysis on the effect of fine water mist curtain blocking fire smoke spreading in subway tunnel. Fire Science and Technology, 38(4): 519-521. https://doi.org/10.3969/j.issn.1009-0029.2019.04.020

[16] Liu, W.Y., Chen, C.H., Shu, Y.L., Chen, W.T., Shu, C.M (2020). Fire suppression performance of water mist under diverse desmoking and ventilation conditions. Process Safety and Environmental Protection, 133: 230242. https://doi.org/10.1016/j.psep.2019.10.019

[17] Li, Q., Tang, Z., Fang, Z., Yuan, J., Wang, J. (2019). Experimental study of the effectiveness of a water mist segment system in blocking fire-induced smoke and heat in mid-scale tunnel tests. Tunnelling and Underground Space Technology, 88: 237-249. https://doi.org/10.1016/j.tust.2019.03.011 
[18] Liang, Q., Li, Y., Li, J., Xu, H., Li, K. (2017). Numerical studies on the smoke control by water mist screens with transverse ventilation in tunnel fires. Tunnelling and Underground Space Technology, 64: 177-183. https://doi.org/10.1016/j.tust.2017.01.017

[19] GB 50016-2014 Code for Fire Protection Design of Buildings. China Planning Press, 2014.

[20] Li, S.L., Li, X.B. (2019). FDS Fire Numerical Simulation. Beijing: Chemical Industry Press.

[21] GB 50084-2017 Code for Design of Sprinkler System.
China Planning Press, 2017.

[22] GB 50898-2013 Technical Specification for Water Mist fire Extinguishing System. China Planning Press, 2013.

[23] Liu, Q., Jiang, X.P., Cai, C.Q. (2013). Analysis of the multiple objective decision of the optimal interval of the exhaust extraction outlets in a centralized tunnel smokeextraction system. Journal of Safety and Environment, 13(2): 214-218. https://doi.org/10.3969/j.issn.10096094.2013 .02 .046 